\title{
Heat Pumps and Its Applications
}

\author{
Arpit Gagneja ${ }^{1}$, and Siddhant Pundhir ${ }^{2}$
}

\begin{abstract}
If you are exploring the heating and cooling options for an industrial liquid or gaseous stream or looking for ways to reduce your energy bills or to minimize the load on non-renewable sources of energy and to preserve it, you should have the ability to adapt to new technologies like Heat Pumps. Most of the chemical plants involve pre-heating of fluids before using it directly in unit processes or unit operations, so there we can use heat pumps to load off the work of boilers by reducing the steam consumption and directly assist in saving on recurring expenditure. It should not be limited to domestic sector only. We can use this technology in waste heat recovery systems of apparently all kinds of chemical plants. Some applications where it is used are drying processes, washing processes, pasteurization and some other also. We must take initiative steps towards the heat pump technology in the industrial sector due to its various benefits and advantages.
\end{abstract}

Keywords - Heat Pumps, Non-renewable energy sources, Chemical Industry.

\section{INTRODUCTION}

Heat pump is a device which pumps heat from, one or more low temperature sources to one or more high temperature sinks simultaneously, with the help of an external source of energy. Heat pumps are designed to move thermal energy opposite to the direction of spontaneous heat flow by absorbing heat from a cold space and releasing it to a warmer one. Heat pumps are very efficient for heating and cooling systems and they can significantly reduce the energy costs. "Heat" is not conserved in this process because it requires some amount of external energy, such as electricity. Heat pumps also work extremely efficiently, because they simply transfer heat, rather than burn fuel to create it and also help in the reduction of greenhouse emission in various industry applications. The most common examples of heat pumps are air conditioners and freezers etc.

All the heat pumps use a refrigerant as a transitional fluid to absorb heat where it vaporizes, in the evaporator, and then to release heat where the refrigerant condenses, in the condenser. The refrigerant flows through the insulated pipes between the evaporator and the condenser, allowing for efficient thermal energy transfer.

The use of heat pumps in the chemical industries in India is limited instead of its huge advantages. The use of heat pumps can save a lot of energy and money. While heat pumps may have lower fuel costs than conventional heating and cooling systems, they are more expensive to buy but it is also very important to realize that heat pumps will be most economical

\footnotetext{
${ }^{1,2}$ Dept. of Chemical Engineering, Pandit Deendayal Petroleum University, Gandhinagar, Gujarat, India
}

when used year round. Generally the heat pumps used in industries start giving paybacks approximately after 1.5-2 years of their installation depending upon their use.

\section{WORKING}

Heat pumps use a volatile evaporating and condensing fluid known as a refrigerant. Refrigerant has low boiling points than all liquids so that only heat source needed is the room temperature fluid. The B.P can be altered by changing the pressure. Initially the refrigerant is a cold and is in low temperature liquid gaseous state flowing through tubes. Refrigerant is responsible for transferring and transporting the heat.

Actual heat gain from the environment or the room temperature liquid takes place from the evaporator. This is where the liquid refrigerant comes into play which boils and evaporates even in sub-zero temperatures. Low pressure vapours are formed by absorbing heat from the air or liquid at room temperature as the liquid refrigerant changes to gas. Once it passes through the evaporator, the refrigerant is a warm gas. Since the refrigerant is not that hot to warm the target liquid, so the compressor comes into the picture. Compressor raises the temperature and pressure of the refrigerant because of the volume reduction and forces the high temperature, high pressure gas to the other heat exchanger called condenser. ${ }^{3}$

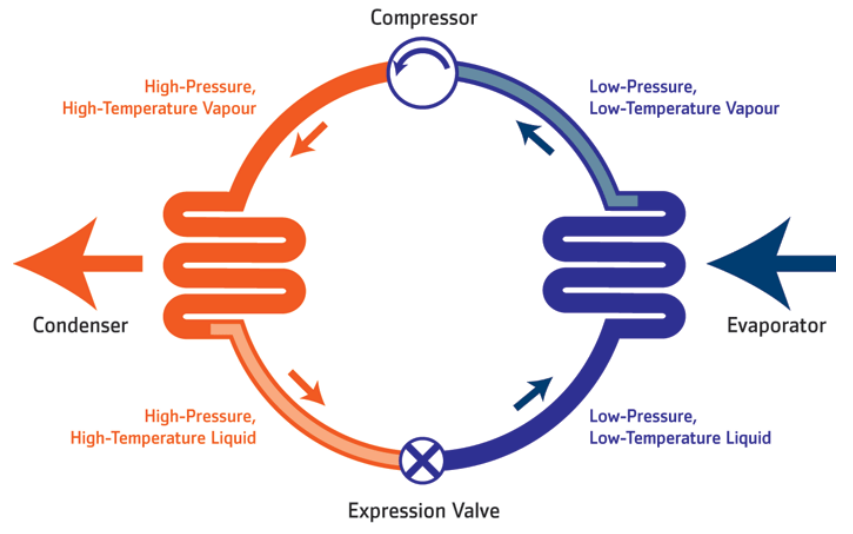

Fig. 1: Heat Pump Cycle

Condenser takes heat from high temperature gas and passes it to the target liquid. By a cooling process, refrigerant again comes to the liquid form which transfers a lot of heat to the liquid and after expansion valve causes reduction in temperature and pressure the ingenious cycle starts once again. 


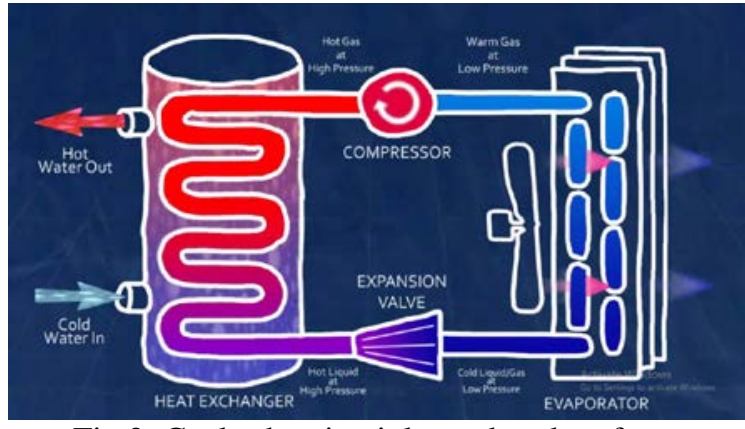

Fig 2: Cycle showing inlet and outlet of streams

\section{HEAT PUMP CLASSIFICATION}

Air to Air

- Cold Utility: comfort air conditioning, cold store operation

- Hot Utility: heating air for drying of clothes, agro products, regeneration of desiccants, etc.

\section{Air to Water}

- Cold Utility: comfort air conditioning, cold store operation

- Hot Utility: heating water, direct heating of process fluids like cleaning solutions in Industrial washing machines, drying agro products, regeneration of desiccants which can be used for taking care of latent cooling load, etc.

\section{Water to Water}

- Cold Utility: comfort air conditioning, precooling of fresh fruits, vegetables or flowers, direct process fluid cooling in chemical, pharmaceutical and food processing industry

- Hot Utility: heating water, direct heating of process fluids like cleaning solutions in industrial washingmachines, drying agro products, regeneration of desiccants which can be used for taking care of latent cooling load, etc. ${ }^{4}$

\section{Water to Air}

- Cold Utility: comfort air conditioning, precooling of fresh fruits, vegetables or flowers, direct process fluid cooling in chemical, pharmaceutical and food processing industry

- Hot Utility: space air heating, heating air for drying of clothes, agro products, regeneration of desiccants, etc.

Heat interactions in the evaporator and the condenser can be with multiple sources and sinks respectively. This enables generating multiple cold and/or hot utilities simultaneously. It also gives greater flexibility to fully tap the benefits of a heat pump..

\section{VARIOUS ApPlications of Heat Pumps}

Heat pumps find their application in various segments of market and industry. Some of its applications are clearly mentioned below:

\section{Market Applications:}

Restaurants, Hotels, Health Clubs, Spas, Hospitals, etc Cold Utility: air conditioning and potable water cooling Hot Utility: heating water for bathing, sanitation, etc

\section{Industrial Applications:}

Dairy, Pharmaceutical, Textile, Food Processing and Cold Stores, Automobile, etc

Cold Utility: air conditioning, process cooling and potable water cooling.

Hot Utility: process heating, boiler feed water preheating, drying, liquid desiccant

\section{ENGINEERING APPLICATIONS OF HEAT PUMPS}

The objective of increasing energy efficiency and reducing operating cost needs to be achieved while simultaneously ensuring high reliability, simplicity of operation and ease of maintenance. The system should have low initial cost or have a short payback period. During our industrial training at Godrej Industries Limited, Valia, we witnessed the use of water to water heat pumps in their processes. The heat pumps used there were compact, easy to operate and user friendly. At Godrej, the payback period was about 1.5 years and they were able to save approximately $\square$ $2,70,000$ per month if all the installed heat pumps work regularly.

One should take into consideration the following points while installing heat pumps:

1)Length of pipelines should not be too long. It causes heat loss through pipes.

2)Water velocities.

3)Refrigerant velocities.

4)Water qualities.

5)Choice of Wetted Material.

\section{Advantages of HeAT PUMPS}

- Heat pumps keep energy costs as low as possible which is the most important thing for any industry.

- Heat pumps require minimal regular maintenance. They have a planned life span of up to 50 years with almost no loss of efficiency, especially when compared to boilers which have $2 \%$ loss of efficiency every year with a usable life span of 12 years.

- Safety and low risk of accidents, considering the danger of conventional heating systems particularly when they are age. Heat pumps are free from contaminants which may cause harm to the environment. It'll help to load off the work of boiler which produces carbon monoxide when faulty, which is harmful to health.

- The basic main advantages is the efficiency of converting energy to heat and the ability to provide heating and cooling at the same time.

- Installation is quite easy.

- Heat pumps are clean, quiet and odourless. It is powered by electricity. 


\section{POSSIBLE APPLICATIONS IN CHEMICAL INDUSTRY}

Petroleum refining and petrochemicals industries

Distillation of petroleum and petrochemicals products in the processes like separation of propane/propylene, butane/butylene, and ethane/ethylene.

\section{Chemical Industries}

- Inorganic salt manufacture including sodium salt sulfate, boric acid, sodium carbonate can use heat pumps in concentrating salt solutions.

- Treatment of effluent process by concentrating waste streams to reduce hydraulic load waste treatment facilities.

- Heat recovery.

- Pharmaceuticals manufacture can use in process water heating.

Wood products

- Pulp manufacturing can use in process like concentration of black liquor.

- Paper manufacturing in process like water heating and flash-steam recovery.

- Lumber manufacturing in product drying.

\section{Food and beverages}

- Activity of manufactures of alcohol like beer brewing, in processes like concentrating waste beer.

- Wet corn milling/corn syrup manufactures can use in concentrating steep water and syrup.

- In Dairy products or Juice manufactures in concentrating their liquid products.

\section{Miscellaneous}

- In Nuclear power stations, it can be used in concentrating radioactive waste and cooling tower blow down.

- In Textiles Industries, processes like wash water heating, space heating and concentration of dilute dope stream.

- Electroplating industries use in heating process solutions and concentrating effluents.

- In other activities like solvent recovery, district heating and steam-stripping of process streams and waste water they are highly used.

\section{VIII.CHALLENGES FOR HEAT PUMPS}

- Heat pumps have very high start-up costs. It's payback time is usually 1.5 or 2 years which highly depends on the purpose it is serving. It will save money in the long run.

- Heat pumps have trouble operating in cold regions. Prolonged exposure in these areas will damage the system and prevent it from running at full efficiency.

- As they run on electricity, continuous and sufficient supply is required.

- Installer and skilled person are required for any damage to the heat pump.

\section{Possible Applications of HeAt Pumps}

\section{A. Distillation Column with Heat Pumps}

- Figure compares the advantages of a distillation plant with heat pump to a conventional unit.

- In a distillation plant with a heat pump, the reboiler and the condenser are linked together.

- The heat pump increases the existing energy in the column head, which is normally dissipated, and transfers it into the reboiler, where the vapour is condensed.

- In comparison with conventional distillation units, this process only requires a fraction of the thermal energy. Furthermore, it does not need any heating steam or large quantities of cooling water.

- Hence by adding heat pump the duty of reboiler and condenser is reduced, hence saving a lot of energy.

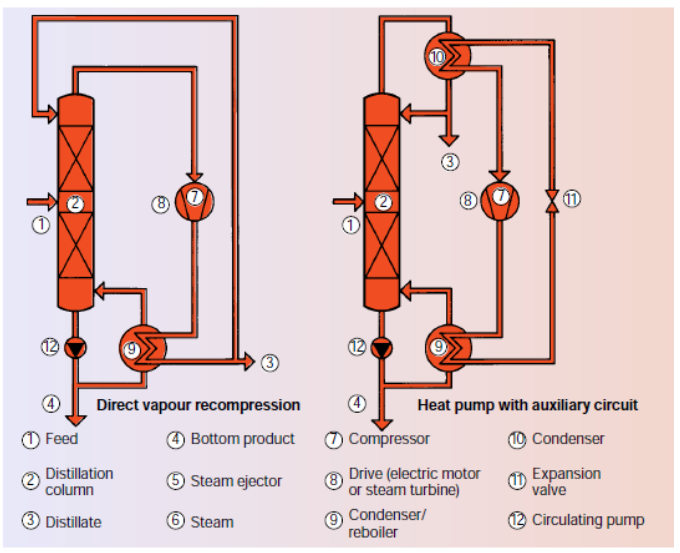

Fig 3: Heat pump in the distillation column

\section{X.CONCLUSIONS}

Energy is essential to life. Without it, many billions of people would be left cold and hungry. The major source of energy comes from fossil fuels, and the dominant fossil fuels used today by most industrialized and developing countries are oil, coal, and natural gas.As world population continues to grow and the limited amount of fossil fuels begins to diminish, it may not be possible to provide the amount of energy demanded by the world by only using fossil fuels to convert energy. There are plenty of ways to convert energy without fossil fuels, and many of are being used, but not nearly to their full potential. One of the ways to convert energy without fossil fuels is by using the Heat Pumps. The use of heat pumps in chemical industries in India is limited. Recent years have shown strong growth in the international heat pump market. Counties likeAustria, Finland, France, Italy, Germany, Norway, Sweden, Switzerland, and the UK are including heat pumps in residential and other applications.

For instance, Figure 4 shows the potential for large scale heat pumps in Germany. From the figure it can be seen that large scale heat pumps have the possibility to provide around $19 \%$ of German total energy consumption in 2005 (EHPAb, 2010). Of these large scale heat pumps, a large potential is in 
the chemical, paper and pulp and food industries. This shows that industrial heat pumps have a considerable potential.

A survey study into the potential of industrial heat pump technology in the food and beverage sector found that a total $\mathrm{CO} 2$ reduction effect of 40 million tonne of $\mathrm{CO} 2 /$ year can be expected from the eleven countries covered by the survey (HPTCJ, 2010). This effect comes from the substitution of steam boilers for heat pumps among applications at a use end temperature below 100 0C. Especially, China (15 million tonne CO2/year) and the United States (14 million tonnes $\mathrm{CO} 2 /$ year) are identified by the survey to have a significant CO2 reduction potential (HPTCJ, 2010).

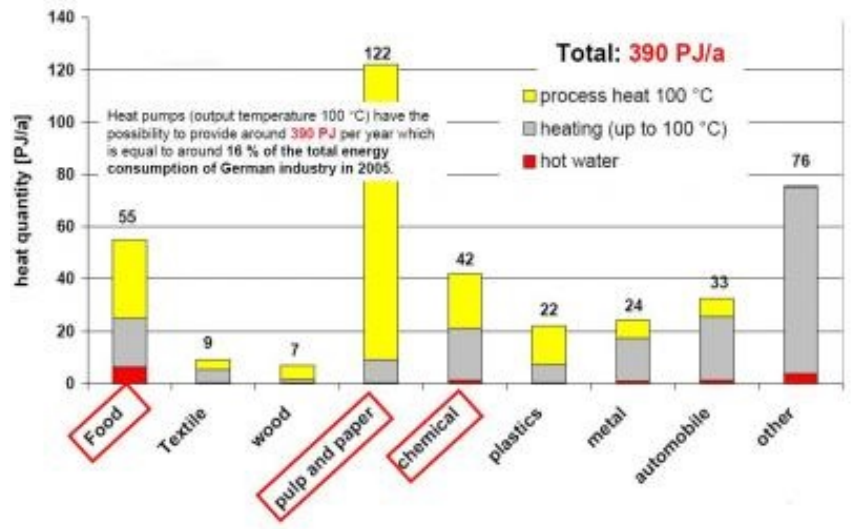

Fig. 4: Potential of large scale applications of heat pumps. The industrial applications of heat pumps in the chemical, paper and pulp and food industries comprise a substantial part of the potential in

Germany. (Source: EHPA b, 2010)

\section{ACKNOWLEDGMENT}

First of all we would like to thank all the faculty members of Chemical Engineering Department of PDPU for their constant support. We are equally thankful to Mr. B.J. Prajapati and Mr.Rajesh Agrawal for their valuable inputs and for providing their precious time to help us learn the basics of heat pumps during our training at Godrej Industries Limited. We would also like to thank Mr. Manish Khodaskar for providing us the opportunity to work in Godrej during our industrial training. We are also thankful to whole team at Godrej Industries Limited, Valia, who had helped us a lot to learn and explore new concepts about heat pumps and its future aspects in the chemical industry.

\section{REFERENCES}

[1] Icarus; " Heat Pump”, created on 2ndAugust 2002, Available from URL: http://en.wikipedia.org/wiki/Heat_pump

[2] Wolf S., "Industrial heat pumps in Germany- potentials, technological development and application examples”, ACHEMA 2012; June 2012.

[3] Agrawal Rajesh S; "Heat Pump- Future Energy Solution for Chemical Industry”, International Journal of Scientific Research and Reviews, 2014; 47-55

[4] Natural Resources Canada's Office of Energy Efficiency; "Heating and Cooling With a Heat Pump"; The National Library of Canada, Cat. No. M144-51/2004E.

[5] Climate Tech Wiki, A clean technology platform, Available from URL: http://www.climatetechwiki.org/technology/jiqweb-ihp

[6] Rexpert, the heat pump expert: Available from URL: https://www.youtube.com/watch?v=KH47xAXEEe0
[7] IEA, 1995. Industrial heat pumps: Experiences, Potential and Global Environmental Benefits. IEA Annex 21 Report of the IEA heat pump centre. Report No. HPP-AN21-1. Document retrieved 17th of November 2010, Available from URL:

[8] http://www.heatpumpcentre.org/en/hpppublications/Sidor/default.aspx. 